\title{
Introduction to Special Issue on Mental Health and Mental Illness in Physical Education and Youth Sport
}

European Physical Education Review 2020, Vol. 26(3) 609-62। (C) The Author(s) 2020 \section{(c) (1) (s)}

Article reuse guidelines: sagepub.com/journals-permissions DOI: $10.1177 / 1356336 \times 20947554$ journals.sagepub.com/home/epe

@SAGE

\author{
Andy Smith (1) \\ Edge Hill University, UK
}

\section{Keywords}

Mental health, physical education, youth, mental illness, children

\section{Introduction: Mental health and mental illness as a problem}

The idea for this special issue of European Physical Education Review preceded the current global Covid-19 pandemic which has unquestioningly exposed and amplified the deeply entrenched inequalities that characterise many countries around the world, and that were already widening before the beginning of the pandemic (e.g. Marmot et al., 2020; Wilkinson and Pickett, 2018). Worsening social, health and educational inequalities have been identified as especially important, and while impacting all social groups, they disproportionately disadvantage the least well-off who are already most vulnerable to poor health (including mental health) and other social problems (Campion et al., 2020; Centre for Mental Health, 2020; Marmot et al., 2020; Wilkinson and Pickett, 2018). In some countries, deaths involving Covid-19 have been shown to be much higher among those in the most deprived communities: in England, between 1 March and 31 May 2020, the agestandardised mortality rate of deaths involving Covid-19 was more than double in the most deprived areas, and in Wales the rate was nearly twice as high (Office for National Statistics, 2020).

As Campion et al. (2020: 1) have noted, the 'rapid global spread of Covid-19 is having wide ranging effects on population mental health', and pandemics such as this are associated with increased risk of mental disorders and poor mental wellbeing. These risks, they argue, are mediated by 'socioeconomic inequalities, poverty, debt, unemployment, food insecurity, social factors, quarantine, physical distancing, and physical inactivity' (Campion et al., 2020: 1), including among children and young people (CYP) and their families. In an educational context, the Education Endowment Foundation (2020) have argued that school closures resulting from the Covid19 related lockdown in the UK, for example, will widen the attainment gap between disadvantaged

\section{Corresponding author:}

Andy Smith, Department of Sport and Physical Activity, Edge Hill University, St Helens Road, Ormskirk, L39 4QP, UK. Email: Andy.Smith@edgehill.ac.uk 
children and their peers, and reverse progress made to narrow this gap since 2011, with median estimates indicating that the gap would widen by $36 \%$. Unequal access to, and knowledge of, digital learning technologies, parents' differential ability to support home schooling, and the impacts of the Covid-19 pandemic on the physical, mental and social wellbeing of school-aged young people, including through decreased physical activity and face-to-face social contact (especially important for peer-oriented adolescents), are among the many other global sources of concern (Education Endowment Foundation, 2020; Orben et al., 2020).

The publication of this special issue during times of a global pandemic is thus timely, but concern about the mental health of CYP and the prevalence of mental illness and suicide in this population, and their connection with various social inequalities (e.g. Pickett and Wilkinson, 2015; Wilkinson and Pickett, 2018), is longstanding. Childhood and youth are important life-stages in which many mental illnesses (e.g. depression, anxiety, eating and substance-use disorders, psychosis) first appear before the age of 24 , where vulnerability to poor mental health and risk of selfharm and suicide progressively increases, and where the start of some mental illnesses have persistent burdens throughout adult life for individuals, communities and societies (Blakemore, 2019; McManus et al., 2019). These life-stages (especially adolescence) are also periods of profound biological, psychological and social change which coalesce with a whole range of adverse childhood experiences (e.g. abuse, neglect, parental mental illness, drug use), the various wellknown risks associated with living in areas of significant socioeconomic disadvantage, and educational and other transitions which characterise childhood and youth (Blakemore, 2019; Marmot et al., 2020; Orben et al., 2020).

Collectively, the complex biopsychosocial changes experienced by CYP contribute to their experience of mental illness, which is estimated to impact $10-20 \%$ of children and adolescents globally (World Health Organization [WHO], 2020), though the patterns and trends vary between and within individual countries. In England, for example, a review of trends in the mental health of CYP concluded that between 1999 and 2017 there had been 'a slight increase over time in the prevalence of mental disorder in 5 to 15 year olds' (NHS Digital, 2018: 8), rising from $9.7 \%$ in 1999 and $10.1 \%$ in 2004 to $11.2 \%$ in 2017 . The prevalence of mental disorders (or illness) in 2017 varied by age and gender: from 1 in 10 (9.5\%: 12.2\% males; 6.6\% females) 5-10-year-olds and 1 in $711-$ 16-year-olds (14.4\%: $14.3 \%$ males; $14: 4 \%$ females) to 1 in $617-19$-year-olds (16.9\%: $10.3 \%$ males; $23.9 \%$ females) (NHS Digital, 2018). Emotional disorders such as anxiety and depression were the most common and increasing conditions reported, and were most prevalent among 17-19-year-olds, where young women $(22.4 \%)$ were three times more likely to be diagnosed with an emotional disorder than young men (7.9\%) (NHS Digital, 2018). Mental disorders were twice as common in non-heterosexual 14-19-year-olds (34.9\%), while reported anxiety was shown to be rising among young girls, but not boys, and was linked to their higher rates of self-harm (21\%) in the late teenage years. Overall, the 2017 data indicated that 1 in 8 6-16-year-olds experience mental illness which becomes progressively more common from childhood to the late teenage years, that mental illness in older teens (but not children) is becoming more common, and that their demand for mental health services has grown significantly (especially in children) (NHS Digital, 2018).

Suicide, which accounts for approximately 800,000 global deaths annually, is also currently the third leading cause of death among 15-19-year-olds (WHO, 2019). It is the leading cause of death among young people in the UK where, despite having a low number of deaths overall, suicide rates among the under-25s have generally increased over the last decade, particularly among 10-24year-old females, where the rate has increased significantly since 2012 to its highest level in 2018 (Office for National Statistics, 2019). Causes of suicide are complex and no two suicide deaths are 
the same, but among the antecedents of suicide in young people which have been identified in the UK are: academic (especially exam) pressures, bullying (face-to-face and online), bereavement, self-harm, physical health conditions, family mental illness, childhood abuse or neglect, alcohol misuse, illicit drug use, and suicide-related internet use (Rodway et al., 2016, 2020). Rates of selfharm in the general population in the UK are rising at a faster rate in girls than boys (Rodway et al., 2020), and engagement in non-suicidal self-harm has also been shown to be increasing in all age groups for males, and especially females, where the highest absolute rises have been in those aged 16-24 largely because of increases in self-cutting (McManus et al., 2019). Particularly significant is the reported increase in using non-suicidal self-harm as a coping strategy by young people, where 1 in 10 have reported engaging in self-harm 'to relieve unpleasant feelings of anger, tension, anxiety, or depression' (McManus et al., 2019: 580) which, if adopted as a long-term behavioural coping strategy, 'could lead in time to increases in suicides and suicide attempts' (McManus et al., 2019: 580).

It is against this backdrop of concern regarding the mental health of CYP and their experience of mental illness that increasing emphasis has been placed globally upon prevention and early intervention in educational policy, and especially the role schools (and individual subjects such as physical education (PE)) and other community settings are believed to play in the promotion of mental health, including as part of universal and targeted programmes to school-based mental health (e.g. Kuosmanen et al., 2019; O'Reilly et al., 2018; Public Health England, 2015). The aim of the special issue is to generate new knowledge on how PE and youth sport (including physical activity and exercise) are being used to address mental health and illness in CYP in schools and related youth sport community settings. It brings together international research which has begun to explore how schools, teachers, coaches and other professionals (including those working in universities) contribute to the mental health of CYP, and which will hopefully stimulate much needed theoretical, conceptual, empirical and methodological research in this increasingly important, yet under-researched and developed, field. The papers which comprise the special issue are outlined later, but it is first worth exploring some key features of the current body of knowledge on mental health in PE and youth sport to help contextualise the issues explored.

\section{Mental health and mental illness in schools and PE}

The links between PE and health promotion have a long history and can be traced back to the activities of the public schools in the nineteenth century, and especially the emergence and development, during the early twentieth century, of physical training in elementary schools (Kirk, 1992). Given the enduring influence of health-based rationales for PE and its perceived contribution to the maintenance and enhancement of health, Cale et al. (2020a: 2) have argued that the contribution of PE to 'healthy active lifestyles is now generally accepted to be a key goal of the subject', and that school-based physical activity - whether delivered during curriculum lessons, before and after school, and/or through PE - is deemed to be critical in developing physically active lifestyles and physical literacy among CYP. Although the precise role PE is thought to play, or should play, in public health promotion (especially in a preventive sense) remains contested (see Cale et al., 2020a; Green, 2020), in the last two decades governments and policy makers in most high-income countries have been increasingly constraining schools and their teachers to contribute towards an expanding and increasingly diverse public health agenda alongside their core educational goals (Smith et al., 2018). In particular, schools and teachers (especially PE teachers) are now simultaneously encouraged to address, and be accountable for, the physical health (e.g. 
overweight and obesity), mental health and wellbeing (psychosocial health), and mental illness (e.g. depression, anxiety, and self-harm) of their pupils, including through PE and other forms of school-based physical activity (Smith et al., 2018).

The expectation that PE teachers will contribute to the health of CYP in their practice is reinforced by various $\mathrm{PE}$ and associated sporting organisations. For example, in its international position statement on PE (endorsed by UNESCO, the International Olympic Committee and International Paralympic Committee), the International Council of Sport Science and Physical Education (2010) claims that engaging in PE enables pupils to develop their physical literacy, 'the skills, attitudes, values, knowledge and understanding for lifelong participation in physical activity and sport', and helps 'develop the patterns of and interest in physical activity, which are essential for healthy development and which lay the foundations for adult healthy lifestyles'. This is a view which is reinforced by the Association Internationale des Écoles Supérieures d'Éducation Physique/International Association for Physical Education in Higher Education (cited in Green, 2020), and the European Physical Education Association (2020), both of whom also emphasise the contribution PE is believed to make to the physical, social, emotional and cognitive development of young people, even though 'the evidence is far from persuasive, let alone conclusive, regarding any of the aforementioned four domains' (Green, 2020: 19). In the UK, the Association for Physical Education (2020) similarly points to the range of health benefits of engaging in physical activity, including through PE, and cites among these: improvements in cardio-respiratory and musculo-skeletal health, maintenance of a healthy weight, enhancements in self-confidence and social skills, and significantly for present purposes, improvements in psychological and mental wellbeing, including positive self-esteem and reduced anxiety and stress.

Notwithstanding the longstanding emphasis which has come to be placed upon the health benefits of engaging in PE, this has until recently focused disproportionately - explicitly, but often and more usually implicitly - on physical health and physically active lifestyles. This is perhaps unsurprising given the lack of parity of esteem between physical and mental health which exists in many aspects of the wider society, and the dominance until relatively recently of physical health over mental health and illness in national policies in related policy areas such as sport (Smith, 2019; Smith et al., 2016). This having been said, in many countries PE (and sport) is increasingly regarded (in policy, if not always in practice) as playing an important role in the promotion of good mental health of CYP, and - through its presentation as a form of physical activity and exercise - in the prevention and treatment of, and recovery from, mental illness. This is captured neatly in the School Sport and Activity Plan in England (though the general point applies to many other countries), which states that:

The importance of physical activity in promoting children and young people's mental wellbeing is ... clear... Physical and mental health are inextricably linked; numerous studies confirm a positive association between physical activity and increased self-esteem, emotional wellbeing and future aspirations, and physical activity is also associated with lower levels of anxiety and depression ... data show us that children who are physically literate are happier, more resilient and more trusting of their peers, and we need to ensure that the importance of physical activity for mental wellbeing is recognised and understood by all young people. (Department for Education et al., 2019: 4)

It should be noted, however, that much of the available evidence on the positive mental health benefits of physical activity for CYP (which is less substantial than it is for adults, Smith et al., 2016) refers specifically to physical activity, rather than PE per se. For example, in their update of 
an earlier review of reviews (Biddle and Asare, 2011), Biddle et al. (2019: 153; added emphasis) noted that 'physical activity is associated with mental health in young people. A causal association can be claimed for cognitive functioning, in part for depression, but not currently for self-esteem', and that more research is needed on the links between anxiety and physical activity in this population group. Significantly, they add that 'it is common to see assertions in national guidelines and educational contexts that physical activity [is] essentially "good" for young people without recognising that positive mental health benefits may depend on the experience of physical activity and the context it takes place in' (Biddle et al., 2019: 147) as well as the various - though not yet well understood - neuro-biological, psychological, and social mechanisms which explain changes in mental health as a result of changes in physical activity (Biddle et al., 2019; Lubans et al., 2016). One such educational context, it might be argued, is PE where there remains a tendency to claim for the subject benefits (e.g. improved mental health) which are currently difficult to demonstrate and which are based on evidence related not to PE, but to the broader dimension of physical activity. School-related physical activity interventions may have small beneficial effects on mental health (Andermo et al., 2020), but we currently know comparatively little about the direct and indirect (as part of school-wide physical activity or sport interventions) contribution participation in PE makes to improvements in pupils' mental health, the mechanisms through which these can be achieved, and the outcomes produced. On the basis of current evidence, an appropriately cautious conclusion in this complex policy area is that engaging in PE may make a positive contribution to aspects of mental health, and may be a helpful component in preventing, treating and recovering from mental illness, but this is likely only to occur under specific circumstances which are not yet well understood, a view which has also been expressed about the evidence base for sport and its impact on mental health (Smith et al., 2016).

There is plentiful evidence from other studies of PE practice, however, which has revealed that rather than promoting positive mental health, some aspects of the content, organisation and delivery of the subject have the potential to impact negatively on pupils' mental health. For example, as Cale (2020) and many others (e.g. Alfrey and Gard, 2014, 2019; Cale and Harris, 2009; Cale et al., 2020a; Harris et al., 2018) have noted, although potentially valuable for pupils' learning and engagement in physical activity, the use of fitness testing within the context of healthbased PE can emphasise individualised and performative practices which have been described as 'counterproductive... unpleasant, uncomfortable, embarrassing and even shaming for many young people, and scores can be inaccurate, misleading, unfair, meaningless and thereby demotivating and detrimental to the confidence of young people' (Cale, 2020: 6) as well as potentially deleterious to their mental health. Other features of the social organisation and construction of contemporary PE practices have also been shown to threaten pupils' mental health, including weighing and measuring practices which exacerbate preoccupations with body weight and image (e.g. Cale and Harris, 2013; Harris et al., 2018; Rich et al., 2020), pupils' engagement in disordered eating and experience of eating disorders (e.g. Evans et al., 2008), and self-surveillance and selftracking practices encouraged by the use of various technological devices and social media (e.g. Goodyear, 2020; Goodyear and Armour, 2019; Goodyear et al., 2019; Lupton, 2020).

The growth of digital media and devices, and their use in settings such as PE, sport and wider fitness contexts in particular, often reproduce dominant ideas about healthism and socially acceptable bodies, and have a significant impact on the construction of health-related forms of knowledge and behaviour (including in relation to mental health) among peer networks (Goodyear, 2020; Goodyear and Armour, 2019). Simultaneously, they are important resources which have become incorporated into many - though not all - young people's lives, identities and 
relationships, and can be important in mental health help-seeking, self-expression and socioemotional learning and regulation (e.g. Goodyear, 2020; Goodyear and Armour, 2019). As Lupton (2020: 2) has noted, however, few studies have so far explored 'how and why young people use digital technologies for health-related purposes and how other, non-digital sources also contribute to the ways in which they learn about their bodies and health and engage in practices to support their health and wellbeing', including their mental health, whether in PE and/or related contexts. It is thus important that we begin to better understand the links between the use of new digital media alongside older technologies (and inequalities in access to these) for mental health, and the degree to which they might contribute to a broadening of pupils' conceptions of health as experienced in and through PE. This is important not least because, up to now, many of the health-related innovations included in the subject are said to have had little impact on pupils' health knowledge, let alone their health-related behaviours (e.g. Green, 2020; Harris et al., 2018).

On a broader front, the poor mental health of young people has been described as a 'widespread and pressing health issue ... which now warrants serious attention' (Cale, 2020: 10) by those in the PE subject community, especially in the design, aims and enactment of PE curricula. In this regard, Cale (2020) has pointed to the growth of interest among researchers in developing pedagogies of affect which enable teachers to support the enhancement of pupils' 'affective attributes including confidence, motivation, determination, self-esteem and resilience through physical education' (Cale, 2020: 10), and in so doing better meet the mental health needs of young people by taking their voices, experiences and life situations more seriously. The growing health-oriented emphasis (often alongside other 'wellbeing' justifications) in PE curricula in which the development of health literacy is regarded as one important outcome can be found in, among other countries, England and Wales (e.g. Green et al., 2018), Scotland (e.g. Kirk et al., 2018), New Zealand (e.g. Burrows and Wright, 2004; Dyson et al., 2018) and Australia (e.g. Macdonald et al., 2018). Commenting upon the health and PE curriculum in Australia, Macdonald et al. (2018: 201) have suggested that the emphasis on health should enable pupils to improve their health literacy and 'become lifelong, critical consumers of health-related information and possess the skills to access, appraise, and apply health-related knowledge'. Such an approach, they argue:

will not solve obesity, physical inactivity, drug misuse, family and community violence, youth suicide... [but] it can educate young people in gaining foundational skills, accessing and appraising resources, and evaluating progress towards living as a health and physically educated citizen. (Macdonald et al., 2018: 202).

Whether any changes (alongside the undoubted and significant continuities) in curricula, including the enactment of pedagogies of affect and embedding of subjects like PE into wholeschool approaches to health and wellbeing, will amount to the desired change in pupils' (mental) health literacy is a moot point on which future research will need to focus. Overall, however, the growing focus on PE as a vehicle of (mental) health promotion in many countries can seemingly be traced to the 'increasing prevalence of physical and mental illnesses for which more exercise is offered as $a$, if not the, main antidote' and the 'fact that sport and PE offer a relatively cheap and easy health-related policy "solution" for governments as well as a ready-made justification for the existence of their subject among physical educationalists' (Green, 2020: 27; emphases in the original). There also now exists, Green (2020: 28) suggests, a 'vibrant lobby for PE as a vehicle for health promotion (among PE teachers and academics alike, as well as among governments and the medical profession)', a pervasive view that PE teachers can and should play a role in 
developing pupils' health literacy, and successive 'generations of PE teachers with an ideological and, to some extent, practical grounding in HRE (health-related exercise)' (Green, 2020: 28). These will likely be among the preconditions for understanding the future relationships between PE, mental health and mental illness, and their relevance for pupils, teachers, researchers and other members of the subject community.

\section{Mental health and mental illness in youth sport}

As Green and Smith (2016) have argued, in some countries and particular social contexts, the term 'youth sport' is often used interchangeably with, and regarded as being inseparable from, schoolbased PE, while in many others it has come to refer to various broader social practices undertaken by young people that extend beyond the kinds of sports and physical activities which are provided in schools. This, they suggest, is related to the increasing disconnection between PE - which is often linked synonymously with 'school sport', and, increasingly, 'physical activity', because of the growing influence of the public health agenda - on the one hand, and 'youth sport' on the other, 'where youth sport is linked to education but not necessarily defined by the activities and priorities of schools and other educational institutions' (Green and Smith, 2016: 2). Notwithstanding the conceptual differences between PE and youth sport, and how these are enacted in practice, it is now just as common for them to be used interchangeably just as they are considered separately, and both are increasingly regarded as important sites for addressing the mental health of young people in many countries.

Over the last decade in particular, there has been a rapid growth in the number, variety and delivery models of community-based mental health programmes located in education and youth sport settings which address mental health. It is impossible to capture the complexity of these here, but these programmes have focused variously on, for example, sport as a context for supporting adolescent male mental health (e.g. Swann et al., 2018), developing mental health awareness in university student athletes (e.g. Breslin, Haughey and Donnelly et al., 2017), the promotion of mental health to coaches (e.g. Breslin et al., 2017), coaches' ability to support the mental health of young people in community sport programmes (e.g. John and Mansfield, 2018; Mazzer and Rickwood, 2009, 2015), and parents' views on the role of coaches in supporting mental health (e.g. Brown et al., 2017; Hurley et al., 2017). These and the many other studies which might be cited are important for, as several authors have noted (e.g. Breslin, Smith and Donohue et al., 2019; Swann et al., 2018; Vella and Swann, 2020), there is a clear need for research which pays greater attention to the mental health needs of those engaged in recreational, community-based sport, including CYP, since it is mental health in elite and professional sport which has until recently typically dominated the research, policy and practice agenda. Indeed, as Swann et al. (2018: 56) have argued, 'little is known about organized youth sport as a vehicle for supporting mental health' and 'more emphasis is required on grassroots sport - involving the largest population of participants and in youth sport where the potential of supporting mental health at an earlier age could have important effects later in life'.

In their review of youth sport and mental health, Faulkner and Tamminen (2016: 414) similarly argued that it is 'difficult to draw clear conclusions regarding youth sport participation and mental health based on the existing evidence'. They suggested that while 'there is good evidence that sport participation, particularly team sport participation, may have a protective effect against depressive symptoms', evidence of the impact of engaging in sport on self-esteem in young people is inconsistent. In this regard, Faulkner and Tamminen (2016: 419) concluded that there may be a need to "re-orient our language from "there is a positive association between sport participation and 
mental health" to the more provisional "there could be a positive association that is achievable under conducive circumstances"'. More programme evaluations, it was claimed, are needed to better understand the various processes, experiences and relationships in youth sport contexts that 'maximise the likelihood that children and youth will experience mental health benefit' (Faulkner and Tamminen, 2016: 419), and those which may be associated with poor mental health. Some of the papers included in this special issue, described next, begin to address this lacuna.

\section{Papers in the special issue}

In the first paper of this special issue, Røset, Green and Thurston (2020) explore 148 Norwegian 15-16-year-olds' experiences of PE in relation to mental health and draw important attention to the various ways in which they are judged, and 'othered', in PE contexts. Drawing upon figurational sociology, Røset and colleagues shed important sociological light on how young people can be judged in relation to their sporting competence and physical appearance, and demonstrate powerfully how the power relations between outsider (those identified by others and themselves as 'less sporty') and insider (those defined as 'sporty' and perceived as physically attractive and fit) groups have important implications for pupils' mental health, self-identities and social status. No less importantly, the socio-cultural significance of sport and (non)sporting bodies in Norway are shown to exacerbate the stigmatising experiences felt by outsider groups, while simultaneously strengthening the ability of more established groups to engage in 'praise gossip' about themselves and impose forms of 'blame gossip' on the sporting outsiders. The authors argue, however, that a nuanced understanding of othering is required to explain the youngsters' experiences, not least because some of them, while not particularly 'sporty' team games players, were established and competent players of lifestyle sports, and many of the less sporty and marginalised outsiders were nevertheless resistant to the attempts made by the more sporty youngsters to impose preferred views on them.

The next paper, by Cale, Harris and Hooper (2020b) reports on the findings of an evaluation of the school-based 'Get to the Start Line' programme designed to address adolescents' schoolrelated stress and anxiety in the East Midlands, UK. This mixed-methods study demonstrates how the programme was effective in reducing wellbeing referrals among the participating youngsters who were known to be experiencing examination-related stress and anxiety. For some pupils, engagement in the programme was associated with reported reductions in stress and anxiety, improved psychological wellbeing and better than predicted performances in their examinations. The programme was thus regarded as an important mechanism which positively influenced pupils' mental health by providing targeted support in school settings, but it was difficult to identify the contribution made by physical activity to reductions in stress and anxiety. In this regard, the findings of this study provide an important opportunity for future studies to reflect upon how schools might engage in programmes of this kind to address the increasing expectation on them to address the mental health of pupils, while maximising examination performance and making progress towards the achievement of other educational attainment targets.

Developing pupils' mental health awareness and socio-emotional learning in schools is the focus of the third paper by Haycock, Jones and Smith (2020) which draws upon data from a schoolbased mental health-themed programme ('Tackling the Blues') for pupils aged 6-16-years-old in north-west England. They provide new evidence on how various pupil-centred learning activities have been used in weekly multi-sport activity sessions and classroom-based workshops to explore pupils' understandings of mental health. The findings demonstrate how engaging in the 
programme led pupils to focus on the impact personal relationships with family and friends, feelings and emotions, and experiences of stress, anger and entrapment can have on mental health, and how these can be managed effectively. The findings also demonstrate how socially relevant learning activities, linked to sport and mental health, might be meaningfully used to improve pupils' knowledge and awareness of mental health, and develop socio-emotional learning in schools. Some of the likely limitations of whole-school approaches to mental health - most notably the wider social inequalities and educational systems-related constraints to which schools are subject - are identified as requiring further attention if we are to adequately address the scale of mental health need in schools.

The fourth paper, by Cecchini, Fernandez-Rio, Mendez-Gimenez and Sanchez-Martinez (2020), examines the associations between levels of physical activity, sedentary behaviour, and self-determined motivation and depressive symptoms in 714 adolescent girls in Spain. Using the International Physical Activity Questionnaire and other instruments, the results demonstrate, among other things, how those girls who engaged in high physical activity levels were 4.5 times less likely to report depressive symptoms than the least physically active, and that a decreased probability of experiencing depressive symptoms was observed among those who were moderately active. Those girls who had the highest probability of experiencing depressive symptoms were also engaged in the highest amount of time spent being sedentary (11 or more hours per day), and the promotion of self-determined motivation is identified as an important means by which PE teachers and health educators can contribute to reductions in depression symptomology.

The final two papers focus on mental health in community youth sport settings. Donohue, Gavrilova, Strong and Allen (2020) address the mental health of youth living in low-income neighbourhoods in the USA who had a recent history of substance use. They demonstrate how engaging in a multi-component optimisation programme, namely, the Family Behavior Therapy/ The Optimum Performance Programme in Sports (FBT/TOPPS), can result in significant reductions in mental health symptoms across a wide range of diagnostic severity levels and multiple drug use in youth up to 21 months post-randomisation. The programme, which focuses on the networks that characterise participants' relationships and which are critical to mental health, is shown to be an important means of enhancing the mental and physical health of youth.

In the final paper, Gorczynski, Gibson, Clarke, Mensah and Summers (2020) examine the little-known links between sports coaches' mental health literacy and their mental health using questionnaire data from 103 coaches in the UK. Approximately two in 10 coaches had previously received a mental disorder diagnosis and one-half indicated that at the time of being surveyed they exhibited symptoms of a mental disorder. Although coaches' mental health literacy was lower than that reported in previous studies, mental health literacy was not significantly associated with coaches' help-seeking behaviour, distress or wellbeing. Given the critical role coaches play in delivering youth sport, and the importance of their own mental health which is often overlooked, the findings of the study have important implications for the design of coach education and development programmes. It also makes clear the need for relevant, accessible and known mental health support services to be made available to coaches to use when needed - whether for themselves, their colleagues or for the young people in their care.

\section{Declaration of conflicting interests}

The author declared no potential conflicts of interest with respect to the research, authorship, and/or publication of this article. 


\section{Funding}

The author received no financial support for the research, authorship, and/or publication of this article.

\section{ORCID iD}

Andy Smith (D) https://orcid.org/0000-0001-9801-3982

\section{References}

Alfrey L and Gard M (2014) A crack where the light gets in: A study of health and physical education teachers' perspectives on fitness testing as a context for learning about health. Asia-Pacific Journal of Health, Sport and Physical Education 5(1): 3-18.

Alfrey L and Gard M (2019) Figuring out the prevalence of fitness testing in physical education: A figurational analysis. European Physical Education Review 25(1): 187-202.

Andermo S, Hallgren M, Nguyen T, Jonsson, et al. (2020) School-related physical activity interventions and mental health among children: A systematic review and meta-analysis. Sports Medicine Open 6: 25.

Association for Physical Education (2020) Health Position Paper. Worcester: Association for Physical Education.

Biddle S and Asare M (2011) Physical activity and mental health in children and adolescents: A review of reviews. British Journal of Sports Medicine 45(11): 886-895.

Biddle S, Ciaccioni S, Thomas G, et al. (2019) Physical activity and mental health in children and adolescents: An updated review of reviews and an analysis of causality. Psychology of Sport and Exercise 42: 146-155.

Blakemore S (2019) Adolescence and mental health. The Lancet 393: 2030-2031.

Breslin G, Haughey T, Donnelly P, et al. (2017) Promoting mental health awareness in sport clubs. Journal of Public Health 16(2): 55-62.

Breslin G, Haughey T, Shannon S, et al. (2019a) The State of Mind Ireland (SOMI) programme for student athletes. In: Breslin G and Leavey G (eds) Mental Health and Wellbeing Interventions in Sport. London: Routledge, pp. 63-73.

Breslin G, Smith A, Donohue B, et al. (2019b) International consensus statement on psychosocial and policyrelated approaches to mental health awareness programmes in sport. BMJ Sport and Exercise Medicine 5: e000585.

Brown M, Vella S, Liddle S, et al. (2017) Parents views of the role of sports coaches as mental health gatekeepers for adolescent males. International Journal of Mental Health Promotion 19(5): 239-251.

Burrows L and Wright J (2004) The good life: New Zealand children's perspectives on health and self. Sport, Education and Society 9(2): 193-205.

Cale L and Harris J (2009) Fitness testing in physical education - a misdirected effort in promoting healthy lifestyles and physical activity? Physical Education and Sport Pedagogy 14(1): 89-108.

Cale L, Harris J and Hooper O (2020a) Debating health knowledge and health pedagogies in physical education. In: Capel S and Blair R (eds) Debates in Physical Education (2nd ed). London: Routledge, pp. 256-277.

Cale L, Harris J and Hooper O (2020b) Get(ting) to the Start Line - the evaluation of an innovative intervention to address adolescents' school-related stress and anxiety. European Physical Education Review 26(3): 642-663.

Campion J, Javed A, Sartorius N, et al. (2020) Addressing the public mental health challenge of COVID-19. The Lancet Psychiatry 9 June, DOI: 10.1016/S2215-0366(20)30240-6

Cecchini J, Fernandez-Rio J, Mendez-Gimenez A, et al. (2020) Connections among physical activity, motivation and depressive symptoms in adolescent girls. European Physical Education Review 26(3): 682-694.

Centre for Mental Health (2020) Covid-19: Understanding Inequalities in Mental Health During the Pandemic. London: Centre for Mental Health. 
Department for Education, Department for Digital, Culture, Media and Sport, and the Department of Health and Social Care (2019) School Sport and Activity Action Plan. London: Authors.

Donohue B, Gavrilova E, Strong M and Allen D (2020) A sport-specific optimization approach to mental wellness for youth in low-income neighborhoods. European Physical Education Review 26(3): 695-712.

Dyson B, Landi D and Gordin B (2018) Redesign of PE in Aotearoa New Zealand. In: Lawson H (ed) Redesigning Physical Education. London: Routledge, pp. 182-195.

Education Endowment Foundation (2020) Impact of School Closures in the Attainment Gap: Rapid Evidence Assessment. London: Education Endowment Foundation.

European Physical Education Association (EUPEA) (2020) European Physical Education Association (EUPEA) Position Statement on Physical Education in Schools, During the Covid-19 Pandemic. Glarus: EUPEA

Evans J, Rich E, Allwood R, et al. (2008) Education, Disordered Eating and Obesity Discourse: Fat Fabrications. London: Routledge.

Faulkner G and Tamminen K (2016) Youth sport and mental health. In: Green K and Smith A (eds) The Routledge Handbook of Youth Sport. London: Routledge, pp. 406-424.

Goodyear V (2020) Narrative matters: Young people, social media and body image. Child and Adolescent Mental Health 25(1): 48-50.

Goodyear V and Armour K (2019) Young People, Social Media and Health. London: Routledge.

Goodyear V, Kerner C and Quennerstedt M (2019) Young people's uses of wearable healthy lifestyle technologies; surveillance, self-surveillance and resistance. Sport, Education and Society 29(3): 212-225.

Gorczynski P, Gibson K, Clarke N, Mensah T and Summers R (2020) Examining mental health literacy, helpseeking behaviours, distress, and wellbeing in UK coaches. European Physical Education Review 26(3): $713-726$.

Green K (2020) Physical education and school sport: Is there a wider social role? In: Capel S and Blair R (eds) Debates in Physical Education (2nd ed). London: Routledge, pp. 18-35.

Green K and Smith A (2016) General introduction. In: Green K and Smith A (eds) The Routledge Handbook of Youth Sport. London: Routledge, pp. 1-4.

Green K, Cale L and Harris J (2018) Re-Imagination and re-design in physical education: Implicit and explicit models in England and Wales. In: Lawson H (ed) Redesigning Physical Education. London: Routledge, pp. 156-170.

Harris J, Cale L, Duncombe R, et al. (2018) Young people's knowledge and understanding of health, fitness and physical activity: Issues, divides and dilemmas. Sport, Education and Society 23(5): 407-420.

Haycock D, Jones J and Smith A (2020) Developing young people's mental health awareness through education and sport: Insights from the Tackling the Blues programme. European Physical Education Review 26(3): 644-681.

Hurley D, Swann C, Allen M, et al. (2017) The role of community sports clubs in adolescent male mental health: The perspective of adolescent males' parents. Qualitative Research in Sport, Exercise and Health 9(3): 372-388.

International Council of Sport Science and Physical Education (2010) International Position Statement on Physical Education. Available at: https://www.icsspe.org/content/international-position-statement-physi cal-education (accessed 23 June 2020).

John A and Mansfield L (2018) Street Games: Safe, Fit and Well - Case Study Research. London: Brunel University.

Kirk D (1992) Defining Physical Education: The Social Construction of a School Subject in Post-War Britain. London: The Falmer Press.

Kirk D, Bardid F, Lamb C, et al. (2018) Redesigning physical education in Scotland. In: Lawson H (ed) Redesigning Physical Education. London: Routledge, pp. 145-155.

Kuosmanen T, Clarke A and Barry M (2019) Promoting adolescents' mental health and wellbeing: Evidence synthesis. Journal of Public Mental Health 18(1): 73-83. 
Lubans D, Richards J, Hillman C, et al. (2016) Physical activity for cognitive and mental health in youth: A systematic review of mechanisms. Pediatrics 138(3): e20161642.

Lupton D (2020) 'Better understanding about what's going on': Young Australians' use of digital technologies for health and fitness. Sport, Education and Society 25(1): 1-13.

McManus S, Gunnell D, Cooper C, et al. (2019) Prevalence of non-suicidal self-harm and service contact in England, 2000-14: Repeated cross-sectional surveys of the general population. The Lancet Psychiatry 6(7): 573-581.

Macdonald D, Enright E and McCuaig L (2018) Re-visioning the Australian curriculum for health and physical education. In: Lawson H (ed) Redesigning Physical Education. London: Routledge, pp. 196-209.

Marmot M, Allen J, Boyce T, et al. (2020) Health Equity in England: The Marmot Review 10 Years On. London: Institute of Health Equity.

Mazzer K and Rickwood D (2009) Community gatekeepers' advice to young people to seek help from mental health professionals: Youth workers and sport coaches. International Journal of Mental Health Promotion 11(2): 13-23.

Mazzer K and Rickwood D (2015) Mental health in sport: Coaches' views of their role and efficacy in supporting young people's mental health. International Journal of Health Promotion and Education 53(2): 102-114.

NHS Digital (2018) The Mental Health of Children and Young People in England, 2017. London: Crown Copyright.

O'Reilly M, Svirydzenka N, Adams S, et al. (2018) Review of mental health promotion interventions in schools. Social Psychiatry and Psychiatric Epidemiology 53(7): 647-662.

Office for National Statistics (ONS) (2019) Suicides in the UK: 2018 Registrations. London: ONS.

Office for National Statistics (ONS) (2020) Deaths Involving COVID-19 by Local Area and Socioeconomic Deprivation: Deaths Occurring Between 1 March And 31 May 2020. London: ONS.

Orben A, Tomova L and Blakemore S (2020) The effects of social deprivation on adolescent development and mental health. The Lancet Child and Adolescent Health, 12 June 2020, DOI: 10.1016/ S23524642(20)30186-3

Pickett K and Wilkinson R (2015) The ethical and policy implications of research on income inequality and child well-being. Pediatrics 135: S39-S47.

Public Health England (PHE) (2015) Promoting Children and Young People's Emotional Health and Wellbeing. A Whole School and College Approach. London: PHE.

Rich E, Monaghan L and Bombak A (2020) A discourse analysis of school girls engagement with fat pedagogy and critical health education: Rethinking the childhood 'obesity scandal'. Sport, Education and Society 25(2): 127-142.

Rodway C, Tham S, Ibrahim S, et al. (2016) Suicide in children and young people in England: A consecutive case series. The Lancet Psychiatry 3: 751-759.

Rodway C, Tham S, Ibrahim S, et al. (2020) Children and young people who die by suicide: Childhoodrelated antecedents, gender differences and service contact. British Journal of Psychiatry Open 6(3): E49.

Røset L, Green K and Thurston M (2020) 'Even if you don't care ... you do care after all': 'Othering' and physical education in Norway. European Physical Education Review 26(3): 622-641.

Smith A (2019) Sports and mental health. In: Maguire J, Falcous M and Liston L (eds) The Business and Culture of Global Sport. New York: Macmillan, pp. 129-143.

Smith A, Green K and Thurston M (2018) Education, physical education and physical activity promotion. In: Piggin J, Mansfield L and Weed M (eds) The Routledge Handbook of Physical Activity Policy and Practice. London: Routledge, pp. 249-258.

Smith A, Jones J, Houghton L, et al. (2016) A political spectator sport or policy priority? A review of sport, physical activity and public mental health policy. International Journal of Sport Policy and Politics 8(4): 593-607. 
Swann C, Telenta J, Draper G, et al. (2016) Youth sport as a context for supporting mental health: adolescent male perspectives. Psychology of Sport and Exercise 35(March 2018): 55-64.

Vella S and Swann C (2020) Time for mental healthcare guidelines for recreational sports: A call to action. British Journal of Sports Medicine, 3 July 2020, DOI: 10.1136/bjsports-2019-101591

Wilkinson R and Pickett K (2018) The Inner Level. London: Allen Lane.

World Health Organization (WHO) (2019) Suicide in the World: Global Health Estimates. Geneva: WHO.

World Health Organization (WHO) (2020) Child and adolescent mental health. Available at: https://www. who.int/mental_health/maternal-child/child_adolescent/en/ (accessed 23 June 2020).

\section{Author biography}

Andy Smith is Professor of Sport and Physical Activity at Edge Hill University, Lancashire, UK. 